Endocrinol. Japon. 1960, 7 (2), $91 \sim 95$

\title{
DIFFERENGE IN RESPONSE BETWEEN UTERUS AND VAGINA TO ESTROGEN GIVEN CONCURRENTLY WITH PROGESTOGEN
}

\author{
KYUTARO MAEKAWA* \\ Department of Histology and Embryology, Tokyo Jikei-kai \\ Medical College, Shiba, Tokyo
}

If sufficient doses of a progestational steroid, e.g. progesterone or a derivative of 19-nortestosterone, was given to ovariectomized rats together with an estrogenic compound, animals exhibited a characteristic response pattern in the vagina (Maekawa, 1955, 1959, 1960; Maekawa et al., 1959). For instance, in animals receiving daily injections of $0.125 \mathrm{mg}$ estrone concurrently with $2.0 \mathrm{mg}$ progesterone for 5 successive days, vaginal estrus which ensued at the beginning of the experiment did not last, being soon replaced by diestrus. After the end of the injection period, however, estrus occurred again in these animals and lasted for a much longer period than in animals receiving $0.125 \mathrm{mg}$ estrone alone for 5 days (Maekawa, 1955). Similar sequence of responses in the vagina also took place when estrogen was injected in combination with 19-nortestosterone derivatives (Maekawa et al., 1959) or when ethinyl-nortestosterone was administered singly. The last mentioned substance has both estrogenic and progestational capacities and the 2 activities of the compound antagonize to each other at certain dose levels (Maekawa, 1959).

Experiments dealt with in the present paper were carried out in order to compare responses of the vagina and the uterus of ovariectomized rats to estrogenprogestogen combinations or to ethinyl-nortestosterone.

\section{MATERIALS AND METHODS}

Procedures of experiments were essentially the same as those described in the previous papers (Maekawa, 1955, 1959; Maekawa et al., 1959).

Adult female rats of Wistar strain were ovariectomized. Beginning at 30 days after operation (day 1 of experiment), 3 groups of the animals, consisting of 32 to 40 rats, were given daily injections of $0.125 \mathrm{mg}$ estrone (Group 1), $0.125 \mathrm{mg}$ estrone and $2.0 \mathrm{mg}$ progesterone (Group 2) and $2.0 \mathrm{mg} 17 \alpha$-ethinyl-19-nortestosterone (Group 3), respectively, for 5 successive days. Two other groups, each comprising 8 ovariectomized rats, received 5 daily injections of $0.5 \mathrm{mg}$ ethinylnortestosterone (Group 4) and $0.125 \mathrm{mg}$ estrone simultaneously with $2.0 \mathrm{mg}$ ethinyl-nortestosterone (Group 5), respectively. The daily doses of the steroids were dissolved in $1 / 8 \mathrm{cc}$ of sesame oil and injected subcutaneously.

Animals in Groups 1, 2 and 3 were sacrificed at days 4, 6, 8, 10, 12 and 15, and those

Received for publication January 20, 1960.

* Present address: Department of Anatomy, Tokyo Medical College, Shinjuku, Tokyo. 
in Groups 4 and 5 at days 6 and 8. Besides these, 12 ovariectomized animals receiving no injections were sacrificed 30 days after ovariectomy (i.e. day 1 of experiment) as controls.

At autopsy, uteri were removed and 2 uterine horns were cut off at the cervical end. One uterine horn was weighed immediately after removing luminal fluid (wet weight), cut into several pieces and fixed in Levi's or Bouin's solution for histologic study. The other horn was desiccated at $70^{\circ} \mathrm{C}$ for 2 days and weighed (dry weight). Two times the values thus obtained were assumed as the wet- and dry-weight of the uterus, respectively, and weights per $100 \mathrm{~g}$ body weight were culculated to facilitate comparison between different groups.

Vaginal smears were carefully examined at autopsy and rated from 0 (perfect anestrus) to 5 (perfect estrus) according to the vaginal indices described in a previoüs paper (Maekawa, 1955).

\section{RESULTS AND DISCUSSION}

Average vaginal indices and uterine wet weights per $100 \mathrm{~g}$ body weight in different experimental groups of animals are presented in Figure 1.

A) Antagonism between estrone and progesterone

Both in the group receiving estrone (Group 1) and that receiving estrone and

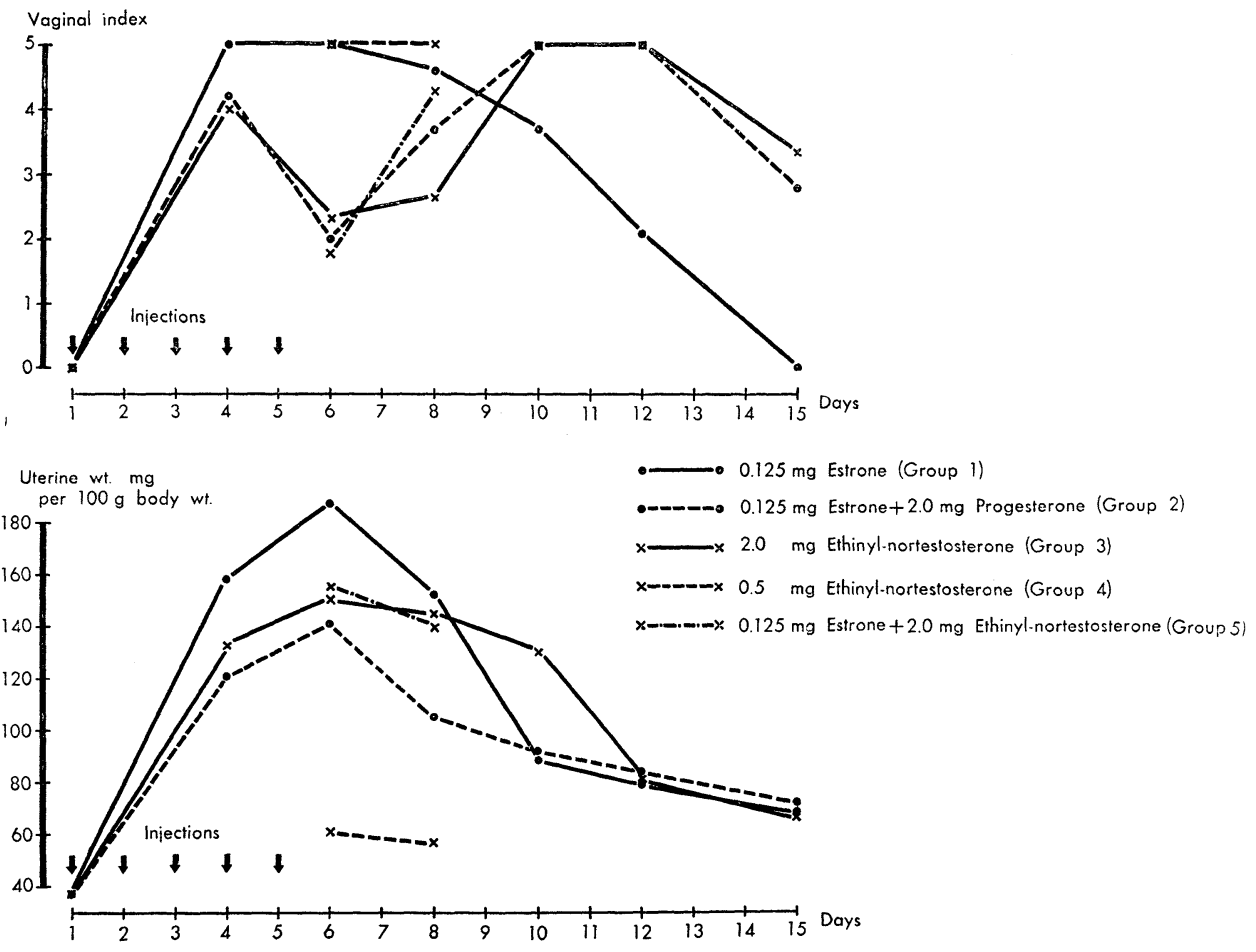

Fig. 1. Changes in average vaginal indices (upper) and in average uterine weights per $100 \mathrm{~g}$ body weight (lower) following injections of $0.125 \mathrm{mg}$ estrone (Group 1), 0.125 $\mathrm{mg}$ estrone together with $2.0 \mathrm{mg}$ progesterone (Group 2), $2.0 \mathrm{mg}$ ethinyl-nortestosterone (Group 3), $0.5 \mathrm{mg}$ ethinyl-nortestosterone (Group 4) and $0.125 \mathrm{mg}$ estrone together with $2,0 \mathrm{mg}$ ethinyl-nortestosterone in ovariectomized rats. 
progesterone (Group 2), changes taking place in vaginal indices during and after the injection period were essentially the same as those reported in a previous paper dealing with similar experiments (Maekawa, 1955). Daily injections of $0.125 \mathrm{mg}$ of estrone induced a perfect cornification of vaginal smear lasting for at least 4 days in all animals (Fig. 1, Group 1). In rats receiving $0.125 \mathrm{mg}$ estrone concurrently with $2.0 \mathrm{mg}$ progesterone (Group 2), vaginal indices fell rapidly after estrus of short duration (vaginal index at day 4 was 4.2), and the animals came to the anestrous state (index at day 6 was 2.0). After this, however, indices rose gradually again up to full estrus (indices at days 10 and 12 were 5.0) and henceforth, in agreement with the findings already reported (Maekawa, 1955), duration of vaginal estrus was markedly prolonged in the estrogen-progesterone group (Group 2) in comparison with that in the estrone group (Group 1) (index at day 12 was 2.1 in Group 1 and 5.0 in Group 2). As shown in Figure 1, therefore, changes in vaginal index in Group 2 plotted on days of experiment depicted a bimodal curve.

In contrast to this, changes in uterine weight, if plotted on days of experiment, depicted a unimodal curve whether animals were given estrone alone or estrone in combination with progesterone (Fig. 1, Groups 1 and 2). Moreover, in Group 2, the maximum weight of the uterus was reached at day 6, when the average vaginal index was smallest.

During the early part of the experimental period, the uteri of animals in the estrone-group were filled with fluid, while those in the estrone-progesterone-group contained hardly any fluid. However, the uteri of estrone-rats were less hyperemic than those of estrone-progesterone-animals.

In a variety of animal species, it is well established that estrogen induces an increase in weight of the uterus and that this increase is impaired by simultaneous administration of progesterone (in mice: Macht and Stickels, 1931; in rats: Korenchevsky and Hall, 1940; Knobil, 1952; in guinea pigs: Mardones et al., 1953; in chickens: Hertz and Tullner, 1950). The antagonism between estrone and progesterone in the effects on the uterine weight was alone observable in the present experiment. The average weights of the uteri per $100 \mathrm{~g}$ body weight in Group 2 at days $4(120.2 \mathrm{mg}), 6(141.0 \mathrm{mg})$ and $8(105.0 \mathrm{mg})$ were significantly smaller than those at corresponding days in Group 1 (158.2, 187.0 and $153.4 \mathrm{mg}$ ) (Fig. 1).

Unlike responses of the vaginae, weights of the uteri of estrone-progesteroneanimals never exceeded those of estrone-animals even toward the end of the experiment (Fig. 1, Groups 1 and 2).

B) Antagonism between estrogenic and progestational activities of ethinyl-nortestosterone

Smear-records of animals receiving $2.0 \mathrm{mg}$ daily of $17 \alpha$-ethinyl-19-nortestosterone were in good agreement with those reported in a previous paper (Maekawa, 1959) (Fig. 1, Group 3). The curve illustrating daily changes in vaginal index in these animals was also bimodal (estrus-anestrus-estrus) like that in animals receiving estrone together with progesterone (Group 2). As discussed previously (Maekawa, 1959), the results with ethinyl-nortestosterone seem to be ascribable to a counteraction between the estrogenic and progestational activities of this steroid or of its metabolites. This hypothesis seems to be supported by the following 
observations.

In the ethinyl-nortestosterone group, response of the uterus, being of the unimodal type, was markedly different in type from that of the vagina (Fig. 1, Group 3). These findings were quite comparable to those in estrone-progesteroneanimals (Group 2). Moreover, the uteri of animals receiving this steroid were invariably hyperemic and contained hardly any luminal fluid at days 4-8, like those of estrone-progesterone-animals.

In a previous paper (Maekawa, 1959) the author has indicated that following daily injections of $2.0 \mathrm{mg}$ or more of ethinyl-nortestosterone a counteraction between the estrogenic and progestational activities of the steroid is always manifested in the response of the vagina of ovariectomized rats, while daily doses smaller than $0.5 \mathrm{mg}$ do not at all produce such an antagonism. In the present experiment, stimulation of the uterus following injections of $0.5 \mathrm{mg}$ ethinyl-nortestosterone for 5 successive days (Group 4) (average uterine weights per $100 \mathrm{~g}$ body weight were $60.0 \mathrm{mg}$ at day 6 and $58.6 \mathrm{mg}$ at day 8 ) was much less than that after $2.0 \mathrm{mg}$ daily of this steroid (152.3 $\mathrm{mg}$ at day 6 and $146.5 \mathrm{mg}$ at day 8 ), while in the vagina the situation was the reverse, that is, at days 6 and 8 vaginal indices were both 5 (perfect estrus) in $0.5 \mathrm{mg}$-animals (Group 4) and 2.3 and 2.6, respectively, in $2.0 \mathrm{mg}$-animals (Group 3).

In Group 5, daily injections of $2.0 \mathrm{mg}$ ethinyl-nortestosterone were as effective as those of $2.0 \mathrm{mg}$ progesterone in inhibiting both vaginal cornification and uterine growth induced by $0.125 \mathrm{mg}$ estrone given concurrently (Fig. 1, Group 5).

Mechanism of counteraction between hormonic steroids has not yet been thoroughly understood. Smith and Smith (1931) reported that in the rabbit progesterone increased urinary excretion of estrogen. However, in similar experiments, Heard et al. (1941) were unable to observe any changes in the excretion of estrogen following administration of progesterone. On the other hand, Pincus (1937), Smith and Smith (1946) and Segaloff (1947) placed emphasis upon the effect of progesterone protecting estrogen from destruction. Richter and Albrich (1952) related the antagonism between estrogen and progestogen to a counteraction between the effects of the steroids on cell permeability, while Roberts and Szego (1946) and Szego (1953) attached importance to a competition between steroids in the formation of complex with proteins.

Anyhow, the results of the present experiments seem to indicate that the antagonism between the estrogenic and progestational activities is a peripheral phenomenon taking place in the target organ. It is hoped to extend these observations in order to clarify the mechanism involved in the steroid hormone antagonism.

\section{SUMMARY}

In ovariectomized rats, daily injections of $0.125 \mathrm{mg}$ estrone together with $2.0 \mathrm{mg}$ progesterone for 5 consecutive days resulted in a quite different sequence of responses between the uterus and the vagina, i.e., changes in vaginal index depicted a bimodal curve (estrus-anestrus-estrus), while those in the weight of the uterus, a unimodal curve. The maximum of the uterine weight occurred 
simultaneously with the smallest vaginal index on the day following the last injection.

Similar difference in type of response between the uterus and the vagina was also observable when ovariectomized rats were given $2.0 \mathrm{mg}$ daily of $17 \alpha$-ethinyl19-nortestosterone for 5 successive days. It appears highly probable that this result is ascribable to antagonism between the estrogenic and progestational activities of this steroid.

These findings seem to suggest that estrogenic and progestational activities antagonize to each other at the level of the target organs.

\section{ACKNOWLEDGMENTS}

The author expresses his hearty thanks to Prof. K. Takewaki of University of Tokyo for valuable suggestions and for criticizing the manuscript. Sincere thanks are also due to Drs. I. Chuman and M. Sawai of Tsurumi Chemical Research Laboratory for kindly supplying ethinyl-nortestosterone.

\section{REFERENGES}

Heard, R. D. H., W.S. Bauld and M.M. Hoffman (1941). J. Biol. Chem. 141, 709.

Hertz, R. and W. W. Tullner (1950). Ann. N.Y. Acad. Sci. 52, 1260.

Knobil, E. (1952). Endocrinology 50, 16.

Korenchevsky, V. and K. Hall (1940). J. Pathol. Bacteriol. 50, 295.

Macht, D. I. and A. E. Stickels (1931). Proc. Soc. Exptl. Biol. Med. 28, 801.

Maekawa, K. (1955). J. Fac. Sci., Univ. Tokyo, Sec. 4, 7, 455.

Maekawa, K. (1959). Endocrinol. Japon. 6, 161.

Maekawa, K. (1960). Annot. Zoo?. Japon. 33. (In press)

Maekawa, K., U. Ito and Y. Ikeda (1959). Zool. Mag. 68, 335.

Mardones, E., R. Iglesias and A. Lipschutz (1953). Experimentia 9, 303.

Pincus, G. (1937). Cold Spring Harbor Symposia Quant. Biol. 5, 44.

Richter, K. and W. Albrich (1952). Wien. Klin. Wochschr. 64, 177.

Roberts, S. and C. M. Szego (1946). Endocrinology 39, 183.

Segaloff, A. (1947). Endocrinology 40, 44.

Smith, G .V. and O. W. Smith (1931). Am. J. Physiol. 98, 587.

Smith, G. V. and O. W. Smith (1946). J. Clin. Endocrinol. 6, 483.

Szego, G. M. (1953). Endocrinology 52, 668. 